\title{
Bacen e BCs selecionados: uma análise comparativa do nível de transparência
}

\author{
Bacen and selected Central Banks: comparative \\ analysis of the transparency degree
}

EDUARDO DE CARVALHO ANDRADE*,***

\begin{abstract}
RESUMO: Resumo: Este artigo compara o grau de transparência do Banco Central do Brasil (Bacen) com o verificado em outros Bancos Centrais (BCs) selecionados. Seguindo a metodologia desenvolvida em Hann e Eijffinger (2000), construímos um indicador de transparência baseado em: (i) quão claros os BCs estão com relação a seus objetivos de política monetária, e (ii) como os BCs são transparentes na implementação de sua política monetária. O Bacen tornou-se mais transparente após a adoção do regime de metas para a inflação em 1999. No entanto, esses procedimentos mais transparentes não fazem parte da lei que regulamenta o Bacen, indicando que eles podem ser facilmente substituídos.

Palavras-chave: Banco central; transparência; política monetária.
\end{abstract}

ABSTRACT: This paper compares the degree of transparency of the Brazilian Central Bank (Bacen) with the one verified in other selected Central Banks (CBs). Following the methodology developed in Hann and Eijffinger (2000), we constructed an indicator for transparency based on: (i) how clear the CBs are with respect to their monetary policy objectives, and (ii) how transparent the CBs implement their monetary policy. The Bacen has become more transparent after adopting the inflation targeting regime in 1999. However, these more transparent procedures are not part of the law that regulates the Bacen, indicating that they can be easily replaced.

KEYWORDS: Central bank; transparency; monetary policy.

JEL Classification: E50; E58.

\section{INTRODUÇÃO}

O conjunto de informações disponível para os responsáveis pela condução da política monetária de um país é bastante complexo. Ele engloba várias ques-

\footnotetext{
* Professor do IBMEC São Paulo. São Paulo/SP, Brasil. E-mail: Eduardo.andrade@ibmec.br. Submetido: fevereiro 2003; aceito: outubro 2003.

** Agradeço a Giovanna Franco Rocca pela excelente assistência nesta pesquisa.
} 
tões como os objetivos do Banco Central (BC), sejam estes de alcançar uma meta inflacionária, manter a taxa de câmbio num determinado patamar, garantir um certo crescimento para um agregado monetário, estimular a economia e reduzir a taxa de desemprego ou qualquer outro. Adicionalmente, o BC tem a sua própria interpretação sobre os fatores que levaram à situação presente da economia e quais são as suas perspectivas futuras, balizadas através da interpretação de diversos tipos de dados macroeconômicos e microeconômicos à sua disposição. Ainda, os policymakers possuem, de forma estruturada ou não, uma visão sobre que política monetária deve-se implantar para alcançar os seus objetivos. Ao mesmo tempo, eles tomam diversas decisões de política monetária, seja em relação às taxas de juros ou câmbio ou intervenções no mercado financeiro. A lista deste conjunto de informações é certamente muito mais extensa e estes são apenas exemplos ilustrativos.

Os demais agentes econômicos não têm conhecimento ou mesmo acesso a todo o conjunto de informações disponível para o BC. O público em geral, por exemplo, nem sempre tem conhecimento do nível de comprometimento da autoridade monetária com a política anunciada, do grau de independência da instituição e das pressões políticas exercidas sobre os seus dirigentes. Nem necessariamente sabe da ênfase que o policymaker atribui para os seus diferentes objetivos, quando das suas decisões de política monetária. Além disso, nem sempre são divulgadas ao público as previsões do BC sobre importantes variáveis macroeconômicas, assim como importantes informações sobre o estado da economia.

O resultado é que existe uma assimetria entre o conjunto de informações disponíveis para os responsáveis pela condução da política monetária no BC e os demais agentes econômicos. É impossível eliminar esta assimetria, principalmente quando se sabe que existem informações confidenciais per se do BC, como aquelas de propriedade de empresas e bancos privados e informações provenientes de outros BCs que não podem ser divulgadas. No entanto, ela pode ser reduzida, e será menor quanto mais transparente for a atuação do BC. Uma possível medida teórica do nível de transparência do BC é exatamente o grau de assimetria entre o conjunto de informações disponíveis para o $\mathrm{BC}$ e para o público em geral. Quanto menor esta assimetria, maior o grau de transparência do BC.

Vários BCs ao redor do mundo têm procurado reduzir esta assimetria nos últimos anos. Isto se deve ao reconhecimento de que uma atuação mais transparente pode aumentar a eficácia da política monetária e até mesmo contribuir para a redução da taxa de inflação. ${ }^{1}$ Adicionalmente, reconhece-se a obrigação de um $\mathrm{BC}$ de prestar contas das suas ações de forma democrática para a sociedade.

\footnotetext{
${ }^{1}$ Ver na próxima seção os argumentos contrários e favoráveis a uma atuação mais transparente de um BC.
} 
Este trabalho analisa o grau atual de transparência do Bacen, comparando-o com o existente antes da adoção do regime de metas de inflação em 1999 e com o verificado em outros BCs selecionados. Segue-se a metodologia utilizada no trabalho de Haan e Eijffinger (2000), que constrói um indicador para mensurar o grau de transparência de um BC. Este indicador analisa dois aspectos principais no que diz respeito à atuação de um BC: a clareza sobre os objetivos de política monetária e a transparência sobre a política monetária implementada. Utilizando este indicador, são comparados dois tipos de BCs: os que adotam e os que não adotam um regime de metas de inflação. Busca-se examinar qual dos dois tipos de BC segue uma postura mais transparente e comparar a atuação do Bacen antes e depois da adoção do regime de metas de inflação. No caso do Bacen, é examinado também se existe alguma diferença entre o seu grau de transparência na prática e aquele exigido pela lei que rege a sua atuação.

Este trabalho possui cinco seções, incluindo esta introdução. Na segunda seção, serão discutidos os benefícios e os custos, apresentados pela teoria econômica, de uma atuação mais transparente por parte de um BC. Em seguida, serão apresentados os enfoques existentes na literatura econômica sobre qual seria o nível ótimo de transparência para uma autoridade monetária. A quarta seção compara o grau de transparência de BCs selecionados, utilizando a metodologia desenvolvida por Haan e Eijffinger (2000). A última seção apresenta a conclusão.

\section{BENEFÍCIOS E CUSTOS DA TRANSPARÊNCIA DO BC}

Esta seção realizará um relato dos principais argumentos teóricos a favor e contra a maior transparência por parte de um BC. Portanto, ela não tem a pretensão de ser completa. Os enfoques abordados nesta e na próxima seção servirão de pano de fundo para a análise sobre o atual nível de transparência do Bacen em comparação com outros BCs.

\subsection{Custos da Transparência}

O exame da atuação dos diversos BCs sugere que, em geral, eles tendem a valorizar a existência de algum tipo de informação privada. Cukierman (1994) apresenta duas explicações teóricas, não mutuamente exclusivas, para um BC ter esta preferência pela manutenção de um certo nível de ambigüidade ou segredo em relação ao seu conjunto de informações. Uma primeira explicação está relacionada à possibilidade, quando na presença de informação privada, de a autoridade monetária criar surpresas inflacionárias com efeitos positivos temporários sobre as variáveis reais da economia, como o nível de atividade e a ta- 
xa de desemprego. ${ }^{2}$ Uma segunda possibilidade está associada ao interesse de políticos de influenciar a política monetária quando um BC possui um estatuto que lhe garante um elevado grau de independência. Neste caso, a existência de informação privada permite que esta influência seja exercida sem que o político incorra num possível risco eleitoral decorrente de possíveis efeitos adversos na economia pela política implantada.

No entanto, parece existir um consenso na literatura econômica de que o BC não deve utilizar o fato de possuir informação privada para surpreender o mercado e afetar, por exemplo, o nível de atividade. Isto decorre do reconhecimento de que estes impactos sobre o nível de atividade são transitórios, de curto prazo. No longo prazo, a política monetária não é capaz de influenciar o nível de atividade e o resultado é somente uma maior taxa de inflação, ${ }^{3}$ que não é desejável. ${ }^{4}$ Portanto, a tentativa de manter a assimetria de informação para “explorar” surpresas inflacionárias é indesejável pois os custos para a sociedade são maiores do que os benefícios transitórios para a autoridade monetária. ${ }^{5}$

Uma outra possível desvantagem de uma maior transparência do BC, possibilitando o mercado entender melhor os seus objetivos, o seu "modelo" da economia e a sua estratégia geral, é a de eliminar a sua flexibilidade na condução da política monetária. Em outras palavras, pode-se pensar, à primeira vista, que a transparência do BC leva-o a ficar "preso", no futuro, a alguma política sinalizada no passado, seja de um maior aperto ou afrouxamento monetário.

No entanto, esta visão não é necessariamente correta. A manutenção da flexibilidade do BC é fundamental e pode conviver com elevado grau de transparência. Se novas informações passam a ser disponibilizadas para o BC, ele deve mudar sua estratégia e sua política monetária, que serão, possivelmente, diferentes das inicialmente planejadas e sinalizadas. Uma grande previsibilidade na forma de atuação do BC, conseqüencia de sua transparência, não elimina a sua capacidade de surpreender o mercado e até mesmo atuar no sentido

\footnotetext{
${ }^{2}$ Cukierman (1994) mostra outros objetivos do BC além de tentar utilizar a sua informação privada para afetar o nível de atividade e a taxa de desemprego. Alguns outros objetivos sugeridos são utilizar surpresas inflacionárias para a obtenção de maiores receitas de seignoriage, menores custos reais do serviço da dívida pública ou metas para o balanço de pagamentos.

${ }^{3}$ Para maiores detalhes, ver Barro (1989).

${ }^{4}$ Sobre um impacto negativo da inflação sobre o bem-estar dos indivíduos, ver Lucas (2000). Jones (1995) analisa teoricamente e mostra evidência empírica dos impactos negativos da inflação sobre a taxa de crescimento da economia.

${ }^{5}$ É aceito que os BCs possam utilizar política monetária para afetar o lado real da economia, contanto que as suas ações não coloquem em risco o objetivo principal da autoridade monetária de manutenção da estabilidade dos preços.
} 
contrário das expectativas dos agentes, quando necessário. Capacidade esta que deve ser mantida e utilizada sempre que necessário. ${ }^{6}$

Um eventual inconveniente é que mudanças constantes nas estratégias ou na sinalização de política por parte do BC, sempre que o seu conjunto de informações se expande, podem minar sua credibilidade. Se o BC for muito detalhista ou específico em sua estratégia, dada a elevada imprecisão dos modelos econômicos, ${ }^{7}$ talvez ele se veja obrigado a reiterá-la e ajustá-la constantemente, aumentado a incerteza dos agentes. Este pode não ser um argumento contrário à transparência do $\mathrm{BC}$, mas talvez indique que não seja desejável que este grau seja extremamente elevado. ${ }^{8}$

Dois trabalhos recentes discutem alguns custos associados à transparência. Jensen (2000) argumenta que uma maior transparência sobre mudanças nos objetivos do BC aumenta a variabilidade das expectativas sobre a inflação dos agentes econômicos. O resultado pode ser uma maior variabilidade na taxa de inflação. Cukierman (2001) mostra que as expectativas inflacionárias são mais voláteis se o mercado possui melhores informações sobre os distúrbios que afetam a economia. Como conseqüência, a taxa de juros pode também ficar mais volátil.

\subsection{Benefícios da Transparência}

Um importante benefício de um nível mais alto de transparência, ao diminuir a assimetria entre o conjunto de informação do $\mathrm{BC}$ e dos demais agentes da economia, é a contribuição que ela pode fornecer para uma redução da taxa de inflação. Cukierman (1994) argumenta (e apresenta evidência empírica) que sinais relevantes (mesmo que imperfeitos) emitidos pela autoridade monetária a respeito da sua política monetária futura, ao reduzirem o grau de incerteza dos agentes econômicos, provavelmente baixam também o nível da taxa de inflação. Outra evidência empírica preliminar que corrobora este ponto teórico é a vivenciada por alguns países que adotaram um regime de metas de inflação no começo da década de 1990. A adoção deste regime na maior parte das vezes é acompanhada por uma maior transparência na atuação do BC, nem que seja somente em relação aos objetivos de política monetária. McCallum (1996) mostra que as médias das taxas de inflação depois que o regime é adotado é menor do que o verificado anteriormente, mas acrescenta que um tempo mais longo é necessário para se chegar a conclusões mais robustas.

Blinder (2000) apresenta um outro ponto a favor de uma maior transpa-

\footnotetext{
${ }^{6}$ Ver Blinder (2000) para uma discussão sobre a relação do mercado com o BC.

${ }^{7}$ Ver discussão em Blinder (2000).

${ }^{8} \mathrm{Na}$ próxima seção, será discutido o nível ótimo de transparência do BC.
} 
rência por parte do BC, qual seja, o de permitir uma maior eficácia da política monetária. Seu argumento é o seguinte: a maior parte dos BCs atualmente controla alguma taxa de juros de curto prazo para alcançar os seus objetivos de política econômica. ${ }^{9}$ Esta exerce uma importante influência sobre as expectativas do mercado sobre as demais taxas futuras de curto prazo que, por sua vez, afetam outras taxas importantes da economia, tais como as taxas de médio e longo prazos, taxa de câmbio, etc. Quanto mais transparente a atuação do BC, as expectativas dos agentes econômicos sobre o que ele fará em relação às taxas futuras de curto prazo são melhor fundamentadas, tornando-as menos voláteis e mais previsíveis. Como decorrência disto, o BC tem maior capacidade de prever a reação da sua política nas demais taxas de mercado que, por sua vez, têm impactos no lado real da economia. Esta maior capacidade de previsão torna mais eficaz a sua própria política monetária. ${ }^{10}$ No limite, um elevado nível de transparência permite ao mercado entender melhor a forma de atuação do BC, podendo o primeiro até antecipar as ações do último.

Uma outra vantagem da maior transparência do BC está ligada a uma redução nos custos de obtenção de informações sobre a política monetária por parte dos demais agentes econômicos. Os benefícios sociais disso são dois. Primeiro, estando os participantes do mercado melhor informados, o nível de informação repassado pelos preços dos ativos financeiros aumenta, o que acarreta um maior bem-estar para a sociedade. Segundo, recursos anteriormente destinados a obter mais informações sobre a forma de atuação do BC podem ser liberados para outros fins. ${ }^{11}$

Uma maior transparência tem um outro importante papel a cumprir, dado que ela é uma parte essencial na obrigação do BC de prestar contas para a sociedade sobre a sua forma de atuação. ${ }^{12}$ BCs em diversas partes do mundo adquiriram a sua independência nos últimos anos, com o reconhecimento de que, desta maneira, eles podem dar prioridade total na obtenção de baixas taxas de inflação. ${ }^{13}$ No entanto, os dirigentes da instituição, diretores e presidentes, não são escolhidos por eleição direta. Estes tecnocratas são nomeados por políticos

\footnotetext{
${ }^{9}$ Por exemplo, o FED e Banco Central do Brasil utilizam, respectivamente, o "Federal funds rate" e a taxa Selic.

${ }^{10}$ Goodfriend (1986) utiliza o mesmo argumento quando diz que, caso a "Directive" do FED fosse liberada, "the market's response would no longer involve guesswork, disclosure would tend to tie the response more closely to policy and thereby make policy effects more predictable from the FOMC's point of view".

${ }^{11}$ Para maiores detalhes, ver Goodfriend (1986) e Grossman e Stiglitz (1980).

${ }^{12}$ Para uma discussão detalhada das diversas facetas do processo relacionado à obrigação de prestação de contas ("democratic accountability") por parte do BC, ver Haan e Eijffinger (2000).

${ }^{13}$ Ver Berger et al. (2000) para uma pesquisa da literatura teórica e empírica sobre a relação entre independência do BC e inflação.
} 
eleitos diretamente pela população e recebem metas a serem cumpridas. Por conseguinte, num regime democrático, eles devem satisfação das suas ações e comportamento para a sociedade, inclusive para justificar a sua própria independência. Sobre este tópico, Blinder (2000) escreve: "The public has a right to demand honesty from its central bankers (...). The central bank owes this to the body politic in return for its broad grant of power. A central bank which dissembles or is imperiously silent is, in my view, behaving in a profoundly undemocratic manner. So are those who would cloak central bank actions in misleading rhetoric”. No caso dos BCs ainda não independentes, como é o caso do Bacen, uma maior transparência pode facilitar o apoio político para a obtenção da própria independência.

\subsection{Comentários Finais}

A discussão anterior apresenta vantagens e desvantagens de uma maior transparência por parte da autoridade monetária. Apesar de ainda não ter sido feita nenhuma estimativa quantitativa dos ganhos e custos de uma maior transparência, pode-se dizer que existe uma tendência na literatura econômica de que o efeito líquido de uma maior transparência é positivo. Walsh (2001) resume este sentimento: "Until there are (quantitative estimates), the general principles that (a) policymakers should strive for clarity and that (b) the public has the right to hold policymakers accountable suggest that recent moves by the Federal Reserve and other central banks to make monetary policy less opaque are positive developments".

À luz da discussão acima, não é surpreendente que os BCs em diversas partes do mundo, nas últimas duas décadas, tenham iniciado procedimentos voltados para, pelo menos parcialmente, abrir seus planos de política para o público. Sobre este assunto, Blinder (2001) diz que: “There can be little doubt that the major central banks of the world - and most of the minor ones as well have moved in the direction of greater transparency over, say, the last 10 years. This trend is unmistakable. I believe it is also irreversible and beneficial". ${ }^{14}$

\section{TRANSPARÊNCIA DO BC: NÍVEL ÓTIMO}

A discussão anterior sugere que, em linhas gerais, uma maior transparência do BC é algo positivo e vem sendo gradativamente implementada nas diversas instituições do mundo. Sabe-se também que total transparência, entendida como o fim da assimetria de informação entre o $\mathrm{BC}$ e os demais agentes

14 Ver Cukierman (1994) sobre algumas indicações de um movimento de maior transparência dos BCs 
econômicos, não é possível. ${ }^{15}$ Isto porque qualquer BC possui informações que, legalmente, não pode revelar para o público. $\mathrm{Na}$ introdução foram mencionados dois exemplos, como informações proprietárias de empresas e bancos privados e informações confidenciais provenientes de outros BCs.

A questão central passa a ser, portanto, qual o nível de transparência ótimo de um BC. O ponto é saber se, eliminando as informações proprietárias e confidenciais, todas as demais disponíveis para o $\mathrm{BC}$, incluindo aquelas que indicam sua forma de atuação nos diversos aspectos relativos à condução da política monetária, devem ser tornadas públicas. Existem alguns estudos na literatura econômica sobre este assunto, que podem ser classificados em dois tipos.

O primeiro tipo pode ser chamado de enfoque "relativo", e propõe que não existe um enfoque "correto" quando o assunto é transparência. Como sugerido por Issing (1999), o nível ótimo de transparência depende do contexto institucional, da tradição do BC e da estratégia de política monetária adotada. O segundo tipo não sugere que o nível ótimo de transparência seja condicionado a qualquer parâmetro ou variável, como o enfoque "relativo". Ele apresenta estratégias que devam guiar a forma de atuação de qualquer BC, independentemente do seu histórico, seu regime monetário ou qualquer outra variável.

A seguir, serão apresentados alguns estudos que exemplificam cada um dos pontos mencionados acima como relevantes do enfoque "relativo". Posteriormente, a atenção será voltada para o enfoque alternativo.

No que se refere ao contexto institucional, Haan et al. (1998) correlaciona o nível ótimo de transparência com o grau de independência do BC. O ponto central é que as expectativas de inflação podem ser reduzidas através de um maior nível de transparência ou de um maior grau de independência do BC. ${ }^{16}$ Desta forma, para um dado objetivo de inflação a ser alcançado, o nível ótimo de transparência é maior quanto menor for o grau de independência do BC. Este último não pode ser alterado rapidamente e, pelo menos no curto prazo, é uma variável tomada como dada pelos responsáveis pela condução da política monetária. Como estes mesmos policymakers têm uma maior autonomia para determinar o grau de transparência do BC, espera-se que eles compensem o menor grau de independência com mais transparência, de forma a facilitar o alcance do seu objetivo de estabilização monetária.

Pode-se utilizar raciocínio análogo ao apresentado acima quando se examina a relação entre a tradição, reputação e credibilidade do BC com o seu nível de transparência. Assim como a independência, a credibilidade também tem o poder de reduzir as expectativas inflacionárias dos agentes e também não po-

\footnotetext{
${ }^{15}$ Para exemplos desta assimetria de informação, ver Greider (1989).

${ }^{16} \mathrm{Na}$ seção anterior, foi discutido o impacto de uma maior transparência sobre o nível da taxa de inflação. Para os impactos do grau de independência do BC sobre a taxa de inflação, ver Berger et al. (2000).
} 
de ser alterada no curto prazo, dado que é algo que só se adquire gradativamente e com um histórico de políticas bem implementadas no passado. Por conseguinte, espera-se que BCs com menor reputação no mercado compensem isto com um maior grau de transparência. Em outras palavras, o nível ótimo de transparência de um BC está também relacionado com sua reputação, além do nível de independência.

Sobre a relação entre transparência e tradição do BC, Issing (1999), no entanto, chama atenção para um importante fato quando examina alguns aspectos institucionais do recém criado Banco Central Europeu (ECB), aspectos que devem ser levados em consideração na atuação de qualquer BC. Este fato está relacionado com a necessidade de o $\mathrm{BC}$ balancear o direito do público em obter informações com a necessidade deste mesmo público de entender as informações disponibilizadas. Segundo ele, é importante que um BC com pouca tradição, com é o caso do ECB, "sends clear and coherent messages to the markets and the wider public. More 'words' do not necessarily mean 'more information', and 'more information' does not necessarily and by itself contribute to greater clarity”.

A mensagem aqui é clara para BCs com pouca tradição. Transparência pode ser um excelente instrumento à sua disposição para compensar a sua pouca reputação. Entretanto, não se deve relegar para um segundo plano a qualidade da informação disponibilizada para os demais agentes econômicos. A clareza é fundamental nas suas explicações para o público.

Além de estar associado ao contexto institucional e à tradição do BC, o nível ótimo de transparência também está relacionado com o regime monetário utilizado. Um bom exemplo é o caso de países que adotam um regime de metas de inflação. Recentemente, vários países instituíram explicitamente um regime deste tipo. ${ }^{17}$

A grande questão que este regime coloca é como determinar se as políticas correntes implantadas são consistentes com a meta de inflação de longo prazo, normalmente metas anuais anunciadas com antecedência de um ou dois anos. Este problema ocorre porque o mecanismo de transmissão da política monetária é demorado, podendo ser de 1,5 a 2 anos o tempo necessário da implementação da política até os seus efeitos serem completamente sentidos. ${ }^{18}$ Como resultado disto, é importante para os BCs que adotam este regime compensarem esta inerente falta de transparência com a utilização de outros mecanismos tais como a publicação de relatórios de inflação, a divulgação das atas das reuniões

\footnotetext{
17 Alguns exemplos são: Brasil, Chile, Finlândia, Grã-Bretanha, Nova Zelândia e Suécia.

18 Ver Artis et al. (1998) para uma breve discussão sobre este assunto.
} 
que decidem as políticas de juros e de informes para a imprensa e participação de sabatinas organizadas por comitês parlamentares. ${ }^{19}$

Adicionalmente, também como decorrência do demorado mecanismo de transmissão da política monetária mencionado acima, um regime de metas de inflação corresponde, na prática, a um regime de meta da previsão de inflação. Segundo Svensson (1997), “(...) the monetary policy conclusions from a given inflation forecast are straightforward: if the forecast is above (below) the target, monetary policy should be adjusted in a contractionary (expansionary) direction. If the forecast is on target, monetary policy is appropriate". Como conseqüência, é importante para o BC sob este regime ser mais transparente, principalmente em relação a suas previsões de inflação, para mostrar que a política implementada está no caminho adequado para atingir a meta especificada, já que a efetiva comprovação do sucesso da política só poderá ser feita $a$ posteriori, um ou dois anos mais tarde. ${ }^{20}$

Pode-se concluir, portanto, que países que adotam um regime de metas de inflação devam ter uma preocupação maior com o grau de transparência do BC. Isto sugere que o nível ótimo de transparência deva ser maior sob este regime. ${ }^{21}$

No segundo tipo de enfoque a respeito do nível ótimo de transparência, um bom ponto de partida é a "regra de bolso" sugerida por Greenspan (1993). Segundo ele, "In a democratic society all public policy making should be in the open, except when such a forum impedes the primary function assigned to the institution". Esta é, no entanto, uma estratégia de cunho bem geral que deve ser entendida como uma linha mestra a ser seguida pelos diversos BCs ao redor do mundo.

Haan e Eijffinger (2000) oferecem alguns critérios mais específicos da estratégia ótima de transparência a ser seguida pelo BC, mas seguindo a linha indicada por Greenspan (1993). Segundo eles, "A 'good' central banker is predictable strategically, but not tactically". Isto implica que o $\mathrm{BC}$ deve ser completamente previsível e transparente para o mercado financeiro sobre as suas estratégias de médio e longo prazos. Assim sendo, o BC tem que ser o mais claro possível em relação às suas metas intermediárias e como pretende alcançá-las. Isto não quer dizer que, no curto prazo, as táticas utilizadas pelo BC tenham que ser transparentes e previsíveis para o mercado. Ao contrário, eles de-

\footnotetext{
${ }^{19} \mathrm{Na}$ próxima seção, será feita uma comparação, seguindo certos critérios, do grau de transparência de dois tipos de BC: aqueles que utilizam o regime de metas de inflação e aqueles que utilizam outros regimes.

${ }^{20}$ Para uma discussão teórica sobre este assunto, ver Bernanke e Woodford (1997).

${ }^{21}$ Em contraste, BCs que adotam um regime de "currency board" não têm que fornecer muitas informações para o público. Basicamente, eles devem apresentar a regra básica que governa o regime e disponibilizar as informações necessárias para o mercado avaliar se esta regra está de fato sendo cumprida. Por outro lado, no caso de um país que segue um regime de "crawling peg”, não é recomendável, por motivos óbvios, que o $\mathrm{BC}$ seja transparente sobre quando e qual será alteração na cotação da moeda.
} 
fendem que o BC deve manter, por exemplo, alguma ambigüidade nas suas intervenções no mercado de câmbio e nas operações de mercado aberto.

Blinder (2001) concorda em parte com a visão de Haan e Eijffinger (2000), segundo a qual as metas intermediárias precisam ser deixadas bem claras para o público, principalmente em função da maior eficácia de política monetária que pode ser conseguida com mais transparência. ${ }^{22}$ No entanto, ele admite possíveis problemas se muita informação for fornecida para os demais agentes econômicos em relação às metas intermediárias. Seu argumento é o seguinte: "the more intermediate targets the central bank posts, the more of them it is likely to miss. Monetary control is, after all, an imprecise art. Such frequent misses are liable to undermine the bank's credibility, which is not only embarrassing to the central bankers but may also make monetary policy harder to conduct".

A conclusão desta seção é que, mesmo desconsiderando as informações proprietárias e confidenciais, não é ótimo, do ponto de vista teórico, o BC seguir uma estratégia na qual ele fornece todas as informações para os demais agentes da economia. Em outras palavras, não é ótimo seguir uma estratégia na qual o grau de transparência é o maior possível. O motivo principal é que esta estratégia pode colocar em risco o próprio cumprimento das funções designadas para a instituição. Sobre este assunto, Blinder (2001) escreve que: "There are indeed limits to central bank transparency. It is not necessary, and indeed may not even be advisable, for the central bank to reveal absolutely everything. But hardly any central banks are, as yet, testing this limit. The trend toward greater transparency in central banking can, should, and (I venture to predict) will continue". Pode-se acrescentar, portanto, que muito pode ser alterado na forma de atuação dos BCs em todo o mundo no sentido de se aproximarem de um nível desejável de transparência.

\section{COMPARAÇÃO DO NÍVEL DE TRANSPARÊNCIA DE BCs SELECIONADOS}

Esta seção realiza um estudo comparativo do nível atual da transparência do Bacen. Sempre que necessário, será feita referência aos argumentos teóricos discutidos anteriormente. Ela é uma adaptação do trabalho de Haan e Eijffinger (2000), que constroem um indicador para mensurar o grau de "democratic accountability" ${ }^{23}$ de cinco BCs. ${ }^{24} \mathrm{Na}$ visão dos autores, o conceito de "demo-

\footnotetext{
${ }^{22}$ Ver seção anterior.

${ }^{23}$ Uma possível tradução para este termo é "obrigação de prestar contas democraticamente".

24 São os seguintes os BCs analisados: Banco do Canadá, Banco do Japão, Banco da Inglaterra, FED e Banco Central Europeu.
} 
cratic accountability" tem três aspectos principais: clareza sobre os objetivos de política monetária, transparência sobre a política monetária implementada e definição sobre quem é o responsável último pela política monetária. Este indicador é construído com base na resposta a treze diferentes perguntas relacionadas com os três aspectos mencionados acima, ${ }^{25} \mathrm{com}$ a pontuação de cada $\mathrm{BC}$ sendo obtida a partir do total de respostas afirmativas às perguntas. Quanto maior a pontuação, maior o grau de "democratic accountability" da instituição. ${ }^{26}$

Como este trabalho pretende abordar a questão da transparência do $\mathrm{BC}$ e tem como foco o Bacen, algumas modificações foram feitas na metodologia empregada em Haan e Eijffinger para se adequar a estes propósitos. Primeiro, foram retiradas as perguntas referentes à definição sobre quem é o responsável último pela política monetária. Isto porque esta discussão faz sentido quando o BC é independente, e não é o caso do Bacen. ${ }^{27}$ Segundo, as questões relativas aos itens clareza sobre os objetivos e transparência da política monetária foram agrupadas e são entendidas como partes complementares e integrantes do conceito de transparência, como apresentado e definido na introdução deste trabalho. Portanto, excetuando as questões referentes à responsabilidade última da política monetária, todas as demais perguntas propostas por Haan e Eijffinger (2000) foram mantidas.

Por fim, os BCs analisados no presente trabalho foram divididos em dois grupos: aqueles que adotam um regime de metas de inflação e aqueles que adotam outro tipo de regime monetário. No primeiro grupo foram incorporados o Banco Central do Chile (BCCh), o Banco Central do México (Banxico), o Bank of England (BoE) e o Reserve Bank of New Zealand (RBNZ), todos independentes, mais o Bacen. O segundo grupo é composto pelos seguintes BCs independentes: Bank of Japan (BOJ), o Bundesbank (o ex-BC da Alemanha), European Central Bank (ECB) e o Federal Reserve Bank (FED). O objetivo aqui é comparar o nível de transparência do Bacen com outros países selecionados que seguem ou não o mesmo regime de metas de inflação utilizado atualmente no Brasil.

Antes de se iniciar a análise comparativa, é importante frisar que a construção deste indicador de transparência, ou seja, a resposta dada para as per-

\footnotetext{
${ }^{25}$ São quatro perguntas sobre os objetivos de política monetária, três perguntas sobre a transparência sobre a política monetária implementada e seis perguntas sobre a definição de responsabilidade da política monetária.

${ }^{26}$ Vale lembrar que as chamadas Regras da Basiléia, que dizem respeito à Supervisão Bancária Eficaz, também tangem a necessidade de transparência das autoridades monetárias, porém sob o viés da disclosure em relação aos riscos. Portanto, é uma abordagem diferente da utilizada por Haan e Eijffinger (2000).

${ }^{27} \mathrm{Na}$ discussão sobre a responsabilidade última pela política monetária, Haan e Eijffinger (2000) focam três questões: na relação do BC com o Parlamento/Congresso, nos procedimentos legais para destituição do presidente do BC (talvez por não cumprir os objetivos estabelecidos) e na existência de algum mecanismo que permita ao governo alterar a política implantada pelo BC.
} 
guntas propostas, é baseada na lei que rege a atuação dos diversos BCs. Em outras palavras, o objetivo deste trabalho é examinar se o arcabouço legal existente obriga ou não a instituição responsável pela condução da política monetária a ser transparente na sua atuação. Este é exatamente o enfoque dado por Haan e Eijffinger (2000), que é seguido aqui.

No entanto, é importante ressaltar, também, que pode existir uma discrepância grande entre o grau de transparência na atuação do BC como exigido pela lei e aquele verificado na prática. Por conseguinte, faz-se necessário, em alguns casos, reexaminar o resultado do indicador de transparência obtido quando se analisa simplesmente o aspecto legal. Isso por dois motivos. Primeiro, porque as leis que regem a atuação de um BC não são necessariamente completas e não estabelecem regras claras sobre as questões relacionadas à transparência. Segundo, mesmo que a lei seja explícita, a prática de um BC pode ser diferente daquela prevista na lei. ${ }^{28}$ Dentre os BCs examinados aqui, dois deles apresentam esta discrepância. Um é o ECB, que é analisado em detalhes em Haan e Eijffinger (2000). O outro é o Bacen, caso que será discutido mais detalhadamente ainda nesta seção.

\subsection{Indicador de Transparência para BCs Selecionados}

As tabelas 1 e 2 apresentam o indicador do grau de transparência para os BCs, respectivamente, que não adotam e que adotam um regime de metas de inflação. ${ }^{29}$

Este indicador é construído com base na resposta dada para seis perguntas. Quanto mais respostas afirmativas para as perguntas propostas um BC possuir, maior é o seu indicador do grau de transparência, ou seja, mais transparente ele é.

As primeiras três perguntas propostas dizem respeito à transparência do $\mathrm{BC}$ em relação aos seus objetivos de política monetária. O intuito aqui é avaliar se (de acordo com o arcabouço legal que rege a sua atuação): (1) os objetivos são estipulados em lei, (2) existe ou não uma clara prioridade dentre os objetivos existentes, e finalmente (3) os objetivos são claramente definidos e quantificados.

As demais perguntas versam sobre um outro aspecto relativo à transparência do BC, qual seja, a obrigatoriedade de divulgar periodicamente explicações sobre sua performance e ações passadas, bem como apresentar seus planos de ações futuras para adequar sua política monetária aos objetivos determinados

\footnotetext{
${ }^{28}$ Este tipo de problema é o mesmo encontrado em estudos sobre o grau de independência de um BC. Aquele grau previsto ou especificado na lei pode diferir em grande medida do verificado na prática. Sobre este assunto, ver Cukierman (1994).

${ }^{29}$ As tabelas 1 e 2 estão no apêndice.
} 
em lei. A intenção é examinar também se o BC informa aos demais agentes econômicos as suas decisões de política monetária e a sua própria percepção sobre a situação corrente e perspectivas da economia.

Com este intuito, três perguntas foram elaboradas. A pergunta quatro examina se o BC publica um Relatório de Inflação ou de política monetária, além dos relatórios e boletins padrão. A pergunta cinco verifica se as minutas das reuniões que decidem a política monetária são publicadas num tempo razoável, a partir do momento em que a decisão é tomada. A sexta, e última pergunta, investiga se o BC é obrigado a explicar publicamente se foi capaz de alcançar os seus objetivos.

A comparação das tabelas 1 e 2 mostra que, com exceção do Bacen, todos os demais BCs selecionados que adotam um regime de metas de inflação, quando examinados do ponto de vista legal, são mais transparentes do que aqueles que adotam outro tipo de regime monetário. O número de respostas afirmativas para as perguntas propostas para os BCs da tabela 2, com exceção do Bacen, está entre cinco e seis. ${ }^{30}$ Para os outros BCs, na tabela 1 , o número está entre dois e quatro. No caso do Bacen, o índice de transparência é igual a um.

Quando se comparam os dois tipos de BCs, não do ponto de vista legal, mas sim observando qual é a sua atuação na prática, observa-se que aqui também o índice de transparência é maior para os BCs que adotam um regime de metas de inflação.

$\mathrm{Na}$ tabela 1 , pode ser visto que o número de respostas afirmativas para as perguntas propostas para os BCs que não seguem um regime de metas de inflação passa a ser entre dois e cinco. Neste grupo de BCs, a única distinção ocorre na atuação do ECB, que na prática é mais transparente do que o exigido pela lei. O seu indicador passa de três para cinco. ${ }^{31}$

\footnotetext{
${ }^{30}$ O RBNZ é constantemente mencionado como o BC com o maior grau de transparência atualmente. Note-se, no entanto, que ele não obtém o indicador máximo de transparência na tabela 2 (seu índice é cinco, sendo o máximo possível igual a seis). A única resposta negativa no caso do RBNZ é a referente à divulgação das minutas das reuniões que decidem a política monetária, o que ele não faz. Entretanto, no caso do RBNZ, não faz sentido a divulgação de uma ata pois seu presidente é o único responsável pela decisão de política monetária. Em outras palavras, não é utilizado um modelo colegiado de tomada de decisão, como no caso do Bacen ou do BoE. Sendo assim, não existe um debate a ser revelado através de minutas. Andrade (2001) discute outros aspectos relacionados à transparência de um BC e apresenta procedimentos utilizados pelo RBNZ, que o colocam como um dos mais transparentes BCs atualmente.

${ }^{31}$ À luz da sua atuação, a única resposta negativa no caso do ECB se refere, assim como no caso do RBNZ, à não divulgação das minutas. Como o modelo adotado pelo ECB é de um colegiado, se justificaria a publicação das minutas, pois ocorre um debate para decidir a política monetária a ser adotada entre os seus membros. A alternativa utilizada pelo ECB, no entanto, é de realizar uma entrevista coletiva (referida às vezes como "President Duisenberg minutes") logo após a decisão da política monetária ser tomada, que não é feita pelos demais BCs selecionados na tabela 2 . Não é óbvio qual é a melhor opção. Portanto, não se pode dizer que, por causa disto, o ECB é menos transparente que os demais BCs que obtiveram um indicador igual a seis. Para maiores detalhes, ver Issing (1999) e Andrade (2001).
} 
Como pode ser visto na tabela 2, agora incluindo o Bacen, o índice de transparência para os BCs que adotam o regime de meta de inflação continua sendo entre cinco e seis, quando se leva em consideração a atuação na prática. O Bacen é o único BC deste grupo que tem o seu indicador alterado. Esta alteração é significativa, passando de um para seis. ${ }^{32}$

Estas duas comparações, feitas do ponto de vista legal e prático, utilizam uma amostra pequena de BCs. No entanto, elas sugerem que os BCs que adotam o regime de metas de inflação tendem a ser mais transparentes do que os outros. À luz da discussão da seção anterior, este resultado é, de certa forma, esperado. ${ }^{33}$ Como vimos acima, como decorrência do demorado mecanismo de transmissão da política monetária, o regime de metas de inflação exige, dos BCs que o adotam, um grau mais elevado de transparência. Estes, por sua vez, parecem corresponder à esta exigência.

\subsection{Indicador de Transparência: o Caso do Bacen}

Como visto acima, o Bacen tem um grau de transparência, na prática, bem superior àquele exigido pela lei que regulamenta as suas atividades. De acordo com o critério proposto, o índice de transparência do Bacen, na prática, é equivalente àquele verificado pelo BoE. Ambos obtiveram o nível mais alto na escala, igual a seis. ${ }^{34} \mathrm{~A}$ grande diferença, portanto, entre estes dois BCs, é que, ao contrário do caso brasileiro, existe na Inglaterra uma lei que obriga o $\mathrm{BoE}$ a cumprir certas obrigações no que se refere ao grau de transparência da sua atuação. Quando se examina a tabela 2, pode-se observar que, do ponto de vista legal, o índice de transparência do BoE também é igual a seis, enquanto o do Banco brasileiro passa a ser igual a um.

Esta comparação com o BoE é importante, pois este é o BC que serviu de modelo inspirador para o Bacen, quando da implantação do regime de metas de inflação no Brasil, em 1999. É interessante examinar detidamente as características legais referentes à atuação do Bacen vis-à-vis o BoE, pois isso pode servir de base para possíveis aperfeiçoamentos na atual legislação brasileira. Principalmente quando o Congresso regulamentar o artigo 192 da Constituição de 1988, que versa, entre outros assuntos, sobre a atuação do Bacen. Nes-

\footnotetext{
32 O Banco Central do Canadá, que não faz parte da amostra selecionada neste trabalho, é um outro exemplo de $\mathrm{BC}$ que adotou recentemente o regime de metas de inflação. Assim como no caso do Bacen, também existe uma enorme diferença entre o grau de transparência exigido pela lei e aquele verificado na prática pelo $\mathrm{BC}$ canadense.

33 Obviamente que, para uma confirmação deste resultado, é necessário realizar uma pesquisa comparativa mais extensa, utilizando um maior número dos dois tipos de BCs. Esta pesquisa mais completa, no entanto, foge do objetivo deste trabalho.
}

${ }^{34}$ Ver tabela 2. 
ta sub-seção, esta comparação se limitará àquelas perguntas que compõem o indicador de transparência sugerido acima. Uma análise complementar será efetuada na próxima seção.

No que se refere aos objetivos de política monetária, enquanto o Congresso não regulamenta o artigo 192 da Constituição, a Lei n ${ }^{\circ} 4.595$ de 31/12/1964 continua em vigor e estipula os objetivos da política monetária. No seu artigo 3, fica determinado que a política do Conselho Monetário Nacional objetivará "adaptar o volume dos meios de pagamento às reais necessidades da economia nacional e seu processo de desenvolvimento" e "regular o valor interno da moeda, para tanto prevenindo ou corrigindo os surtos inflacionários ou deflacionários de origem interna ou externa, as depressões econômicas e outros desequilíbrios oriundos de fenômenos conjunturais".

Do acima exposto, fica claro, portanto, que a atual lei que rege a atuação do Bacen estipula os objetivos da política monetária. Pode-se depreender do texto que existem, na verdade, múltiplos objetivos, como controlar a inflação, impedir depressões econômicas e criar condições que permitam o desenvolvimento econômico. ${ }^{35}$

A Lei ${ }^{\circ} 4.595$ não estipula prioridades dentre os objetivos de política monetária existentes e nem define claramente ou quantifica os mesmos. Estas são as outras perguntas sobre os objetivos de política monetária, que constam do indicador de transparência proposto acima.

É interessante comparar a legislação brasileira com a lei que regulamenta a atuação do BoE, o "Bank of England Act" de 1998. O contraste com as questões abordadas até agora é grande, pois esta última vai além de simplesmente indicar os objetivos de política monetária. Primeiro, uma prioridade é claramente estabelecida. Sobre isto, a lei determina que "the objectives of the Bank of England shall be (a) to maintain price stability, and (b) subject to that, to support the economic policy of Her Majesty's Government, including its objectives for growth and employment." ${ }^{36}$ Segundo, a lei indica como será definido e quantificado o objetivo de política monetária, pois estabelece que o Tesouro deve estabelecer estes parâmetros e informá-los ao BoE.

Quando da implantação do regime de metas de inflação, em junho de 1999, o governo brasileiro lançou o Decreto $n^{\circ} 3.088$, de 21/6/1999, que segue de perto a estrutura existente no "Bank of England Act". Este decreto fecha as lacunas existentes na Lei ${ }^{\circ} 4.595$ sobre os pontos mencionados acima, quanto à ausência de prioridade, clara definição e quantificação dos objetivos de política monetária.

\footnotetext{
${ }^{35}$ Os Estados Unidos também possuem uma legislação com múltiplos objetivos. Fica estipulada nela que o FED deve direcionar a sua política monetária para alcançar nível de emprego máximo e estabilidade dos preços.

${ }^{36}$ Grifo nosso.
} 
O Decreto, dentre outros pontos, estabelece "como diretriz para fixação do regime de política monetária, a sistemática de "metas para a inflação'", indicando como será definida a meta e os respectivos intervalos de tolerância. Além disto, ele estipula que ao Bacen "compete executar as políticas necessárias para cumprimento das metas fixadas".

A partir de 1999, o Bacen passou a atuar alinhado com as determinações do Decreto mencionadas acima. Desta forma, com a sua adoção, as respostas para as perguntas dois e três propostas no indicador de transparência passam a ser afirmativas, quando se examina, na prática, a atuação do Bacen.

No que se refere às questões quatro a seis, que fazem parte do indicador de transparência acima discutido, a Lei n ${ }^{\circ} 4.595$ não estabelece que o Bacen tenha que: publicar um Relatório de Inflação ou política monetária, divulgar as minutas das reuniões que decidem a política monetária ou se explicar publicamente se foi capaz ou não de alcançar os seus objetivos. Por isto, as respostas para estas perguntas foram negativas quando foi calculado o índice de transparência do Bacen, do ponto de vista legal.

Em contraste, o "Bank of England Act" estabelece que o BoE deve tornar públicas as minutas de cada reunião do seu Comitê de Política Monetária num prazo de até seis semanas, contadas a partir do dia do encontro. Ao mesmo tempo, ele indica que o BoE fica obrigado a publicar, trimestralmente, um Relatório de Inflação. Deste relatório devem constar, para o período examinado, entre outros pontos: (a) uma revisão das decisões de política monetária, (b) uma avaliação da trajetória da inflação e (c) uma indicação de qual enfoque se deve esperar da autoridade monetária para que os objetivos de política monetária sejam alcançados. Por fim, o "Bank of England Act” estipula que o BoE é obrigado a se explicar publicamente se foi capaz de alcançar os objetivos estabelecidos em lei.

Novamente, quando da implantação do regime de metas de inflação em 1999 , foram fechadas estas outras lacunas da Lei ${ }^{\circ} 4.595$, no que se refere às questões quatro a seis do indicador de transparência. Os instrumentos utilizados foram o Decreto n ${ }^{\circ} 3.088$ e a Circular n 3.010, de 17/10/2000. Mais uma vez, estas alterações seguem de perto a estrutura do "Bank of England Act".

O primeiro estipula que o Bacen "divulgará, até o último dia de cada trimestre civil, Relatório de Inflação abordando o desempenho do regime de 'metas para a inflação', os resultados das decisões passadas de política monetária e a avaliação prospectiva da inflação". Além disto, ele determina que "caso a meta (de inflação) não seja cumprida, o Presidente do Banco Central do Brasil divulgará publicamente as razões do descumprimento, por meio de carta aberta ao Ministro de Estado da Fazenda”. Por sua vez, a Circular estabelece que "as atas das reuniões do Copom (Comitê de Política Monetária) serão divulgadas no período de seis dias úteis após a sua realização".

Quando se leva em consideração estas modificações introduzidas pelo De- 
creto e pela Circular, as respostas para as três últimas perguntas do indicador de transparência passam a ser positivas.

É importante ressaltar que os ganhos de transparência mencionados acima (com as respostas das perguntas 2 a 6 passando a ser positivas) ocorreram a partir de 1999, com a implantação do regime de metas de inflação. No período imediatamente anterior, da implantação do Plano Real, em 1994, até 1999, por exemplo, a atuação do Bacen foi muito mais opaca: das seis perguntas propostas, a resposta era afirmativa somente para a primeira, que consta na Lei 4.595 de 1964.

É importante também frisar que as diretrizes que constam tanto do Decreto $\mathrm{n}^{\circ} 3.088$ quanto da Circular $\mathrm{n}^{\circ} 3.010$, mencionadas acima, obviamente, não fazem parte da Lei 4.595 que rege a atuação do Bacen. Os responsáveis pela condução da política monetária a partir de 1999 decidiram incorporar estas importantes mudanças de procedimento, indo muito além do que o especificado pela lei. Como decorrência disto, no entanto, estes ganhos de transparência, relativos à condução da política monetária e alcançados desde a implantação do regime de metas de inflação, podem ser facilmente perdidos. Isto pode ocorrer pois é extremamente fácil para uma nova administração alterar o Decreto ou a Circular e modificar as regras neles contidas que balizam atualmente importantes aspectos da política monetária. O mesmo, obviamente, não aconteceria se estes aspectos estivessem já incorporados na lei pois, neste caso, modificações são bem mais difíceis de serem implementadas.

A mudança na lei, incorporando os aspectos discutidos acima, que já constam ou em decreto ou em circular, seria um avanço significativo no atual arcabouço legal que rege o funcionamento do Bacen. Este passo importante poderia ser tomado quando da regulamentação do artigo 192 da Constituição. A legislação que estabelece as diretrizes da atuação do BoE serve como um bom exemplo a ser seguido.

\section{CONCLUSÃO}

Este trabalho procurou examinar o atual nível de transparência do Bacen, comparando os seus procedimentos e a sua forma de atuação com outros BCs selecionados.

Inicialmente, para servir de pano de fundo para a análise comparativa posterior, realizou-se uma revisão da literatura econômica sobre o tema. Primeiro, os benefícios e os custos de uma maior transparência da autoridade monetária foram apresentados. Em seguida, discutiu-se qual o seu nível ótimo.

A discussão teórica apresentada sugere que, de um modo geral, uma atitude de maior transparência por parte do BC é benéfica pois reduz o grau de incerteza dos agentes econômicos, contribuindo para uma maior eficácia na po- 
lítica monetária e, até mesmo, para a redução do nível da taxa de inflação. Ao mesmo tempo, ela diminui o grau de liberdade do responsável pela política monetária para gerar surpresas inflacionárias para satisfazer outros objetivos de política monetária, o que não é necessariamente desejável do ponto de vista do bem-estar da sociedade. Ainda não existe um estudo empírico que estime os benefícios e os custos da transparência. No entanto, a literatura econômica teórica parece sugerir que os procedimentos adotados nos últimos anos em diversos BCs, de seguir uma política monetária mais transparente, são desejáveis.

Nossa discussão também aponta que não é uma política ótima, por parte do BC, seguir uma estratégia na qual o grau de transparência seja o maior possível. Em outras palavras, conclui-se que, mesmo desconsiderando as informações proprietárias e confidenciais, não é ótimo o BC seguir uma estratégia na qual ele forneça todas as informações para os demais agentes econômicos. $\mathrm{O}$ motivo principal é que esta estratégia pode colocar em risco o próprio cumprimento das funções designadas para a instituição. No entanto, ainda não existe nenhum BC testando este limite ótimo de transparência. Portanto, muito pode ser alterado na forma de atuação dos BCs no sentido de se aproximarem de um nível desejável de transparência.

Em seguida, foi realizada a análise comparativa do atual nível de transparência do Bacen. Seguindo a metodologia utilizada em Haan e Eijffinger (2000), foi construído um indicador de transparência que analisa dois aspectos relativos à atuação de um BC: a clareza sobre os objetivos de política monetária e a transparência sobre a política monetária implementada. Foram elaboradas seis perguntas sobre estes tópicos. Segundo o critério definido, um BC é considerado mais transparente quanto maior é o número de respostas afirmativas para estas perguntas. O resultado obtido mostra que os BCs que utilizam um regime de metas de inflação, dentre eles o Bacen, são em geral mais transparentes. Este resultado é, de certa forma, esperado. Como decorrência do demorado mecanismo de transmissão da política monetária, o regime de meta de inflação exige, dos BCs que o adotam, um grau mais elevado de transparência.

No caso do Bacen, verificou-se uma discrepância grande entre o grau de transparência exigido pela lei e aquele verificado: na prática, o Bacen é mais transparente do que o exigido pela lei. Depois da implantação do regime de metas de inflação, o Bacen passou a adotar vários procedimentos que o tornaram mais transparente. Dentre outros, estipulou-se uma prioridade dentro os seus objetivos de política monetária, passou-se a tornar públicas as atas das reuniões do Copom e a divulgar trimestralmente um Relatório de Inflação. Estas e outras modificações foram implementadas através de decreto ou de circular. Portanto, estes procedimentos não constam da lei que rege a sua atuação e não existe uma garantia de sua manutenção no futuro. 


\section{APÊNDICE}

Tabela 1: Indicador de transparência para BCs selecionados que não adotam um regime de metas de inflação

\begin{tabular}{lcccc}
\hline \multicolumn{1}{c}{ Perguntas } & BOJ & ECB & Fed & Bundesbank \\
\hline 1) A lei do BC estipula os objetivos de política monetária? & Sim & Sim & Sim & Sim \\
\hline $\begin{array}{l}\text { 2) Existe uma clara prioridade de objetivos? } \\
\text { 3) Os objetivos são claramente definidos e quantificados? }\end{array}$ & Não & $\begin{array}{c}\text { Não } \\
\text { (Sim) }\end{array}$ & Não & Não \\
\hline $\begin{array}{l}\text { 4) O BC é obrigado a publicar um Relatório de Inflação } \\
\text { ou de política monetária além dos relatórios e boletins } \\
\text { padrão? }\end{array}$ & Não & Não & Sim & Não \\
$\begin{array}{l}\text { 5) As minutas das reuniões que decidem a política } \\
\text { monetária são publicadas em tempo razoável? }\end{array}$ & Não & Não & Sim & Não \\
\hline $\begin{array}{l}\text { 6) O BC é obrigado a explicar publicamente se foi capaz } \\
\text { de alcançar os seus objetivos? }\end{array}$ & Sim & Sim & Sim & Não \\
\hline \begin{tabular}{l} 
Total de respostas afirmativas: \\
\hline
\end{tabular}
\end{tabular}

Fonte: Haan e Eijffinger (2000) e Haan, Amtenbrink e Eijffinger (1998).

Obs: Os números entre parênteses no caso do ECB indicam os resultados obtidos a partir de sua atuação prática.

Tabela 2: Indicador de transparência para BCs selecionados que adotam um regime de metas de inflação

\begin{tabular}{lcccccc}
\hline \multicolumn{1}{c}{ Perguntas } & Banxico & BoE & BCCh & Bacen & RBNZ \\
\hline 1) A lei do BC estipula os objetivos de política monetária? & $\operatorname{Sim}$ & $\operatorname{Sim}$ & $\operatorname{Sim}$ & $\operatorname{Sim}$ & $\operatorname{Sim}$ \\
\hline $\begin{array}{l}\text { 2) Existe uma clara prioridade de objetivos? } \\
\text { 3) Os objetivos são claramente definidos }\end{array}$ & $\operatorname{Sim}$ & $\operatorname{Sim}$ & $\operatorname{Sim}$ & Não & $\operatorname{Sim}$ \\
$\begin{array}{l}\text { e quantificados? } \\
\text { e }\end{array}$ & $\operatorname{Sim}$ & $\operatorname{Sim}$ & $\operatorname{Sim}$ & Não & Sim \\
\end{tabular}

4) O BC é obrigado a publicar um Relatório de Inflação ou de política monetária além dos relatórios e boletins $\quad \operatorname{Sim} \quad \operatorname{Sim} \quad$ Não $\quad \operatorname{Sim}$ padrão?

(Sim)

5) As minutas das reuniões que decidem a política monetária são publicadas em tempo razoável?

Não Sim Não Não Não

(Sim)

6) O BC é obrigado a explicar publicamente se foi capaz de alcançar os seus objetivos?

$\operatorname{Sim} \operatorname{Sim} \operatorname{Sim}$ Não $\operatorname{Sim}$

(Sim)

Total de respostas afirmativas:

$\begin{array}{lllll}5 & 6 & 5 & 1(6) & 5\end{array}$

Fonte: Haan e Eijffinger (2000) para o BoE; Haan, Amtenbrink e Eijffinger (1998) para o RBNZ e elaboração própria para o BCCh, Banxico e o Bacen.

Obs: Os números entre parênteses no caso do Bacen indicam os resultados obtidos a partir de sua atuação prática. 


\section{REFERÊNCIAS BIBLIOGRÁFICAS}

ANDRADE, E. (2001), “Bacen e BoE: uma Análise Comparativa do Nível de Transparência”, Ibmec Working Papers.

ARTIS, M., MIZEN, P. e KONTOLEMIS, Z. (1998), "Inflation Targeting: What Can the ECB Learn from the Recent Experience of the Bank of England?”, The Economic Journal, November, pp. 1.8101.825.

BARRO, R. (1989), Modern Business Cycle Theory, Harvard University Press.

BERGER, H., HAAN, J. e EIJFFINGER, S., (2000), “Central Bank Independence: An Update of Theory and Evidence", CEPR Discussion Paper, $\mathrm{n}^{\circ}$ 2353, January.

BERNANKE, B. e WOODFORD, M. (1997), "Inflation Forecasts and Monetary Policy", Journal of Money, Credit and Banking, November, vol. 29, nº 3, pp. 653-684.

BLINDER, A. (2000), Central Banking in Theory and Practice, MIT Press, Cambridge, Mass.

(2001), "Transparency in Central Banking”, Economic Letter, CSFB Garantia, June. CUKIERMAN, A. (1994), Central Bank Strategy, Credibility, and Independence - Theory and Evidence, The MIT Press.

GOODFRIEND, M. (1986), “Monetary Mystique: Secrecy and Central Banking”, Journal of Monetary Economics, vol. 17, pp. 63-92.

GREENSPAN, A. (1993), Statement before the Committee on Banking, Finance, and Urban Affairs, U.S. House of Representatives, October.

GREIDER, W. (1989), Secrets of the Temple: How the Federal Reserve Runs the Country, New York: Touchstone.

GROSSMAN, S. e STIGLITZ, J. (1980), “On the Impossibility of Informationally Efficient Markets”, American Economic Review, n 70, pp. 561-574.

HAAN, J., HOEBERICHTS, M. e SCHALING, E. (1998), “A Theory of Central Bank Accountability”, CEPR Discussion Paper, $\mathrm{n}^{\circ}$ 2.354, January.

HAAN, J. e EIJFFINGER, S. (2000), "The Democratic Accountability of the European Central Bank: A Comment on Two Fairy-tales”, Journal of Common Market Studies, September, vol. 38, n 3, pp. 393-407.

ISSING, O. (1999), “The Eurosystem: Transparent and Accountable or Willem in Euroland?”, Journal of Common Market Studies, September, vol. 37, n 3, pp. 503-519.

JENSEN, H. (2000), “Optimal Degrees of Transparency in Monetary Policymaking”, Univeristy of Copenhagen, December.

JONES, L. e MANUELLI, R. (1995), "Growth and the Effects of Inflation”, Journal of Economic Dynamics and Control, November, vol. 19, pp. 1.405-1.429.

LUCAS, R. (2000), “Inflation and Welfare”, Econometrica, March, vol. 68, pp. 247-274.

SVENSON, L. (1997), "Inflation Forecast Targeting: Implementing and Monitoring Inflation Targets”, European Economic Review, no 41, pp. 1.111-1.146.

WALSH, C. (2001), “Transparency in Monetary Policy”, FRBSF Economic Letter, Number 2001-26, September. 